\title{
8
}

\section{La Financiación de las Sociedades Cooperativas}

\author{
José Eduardo Souza de Miranda \\ Doctorando en Derecho \\ Becario Cátedra UNESCO de Formación \\ de Recursos Humanos para América Latina
}

El hombre es la medida

de todas las cosas, de las que son, en cuanto son, $y$ de las que no son en cuanto no son

Protágoras de Abdera

Para el humano el bien general solamente parece ser bien en cuanto posible comprensivo, por extensión, de su propio bien. Pero estará ordinariamente de acuerdo, sin embargo, en que si todo va bien pero a él le va mal, todo va mal. Y por el contrario, si todo va mal pero a él le va bien, todo va bien.

Javier Divar 
Sumario: Introducción.-I. La Sociedad Cooperativa: generalidades. I.1. El concepto de cooperativa. I.2.La cooperativa empresa y la cooperativa empresario.--II. La Financiación de las Sociedades Cooperativas. II.1. Planteamiento general. II.2. La estructura económica de la cooperativa. II.2.1. Los fondos propios. II.2.1.1. El capital social. a) Las aportaciones obligatorias. b) Las aportaciones voluntarias. c) La transmisión y el reembolso de las aportaciones. d) La actualización de las aportaciones. II.2.1.2. Los excedentes no repartidos. a) Determinación de los excedentes. b) El fondo de reserva obligatorio. c) Los fondos de reserva voluntarios. II.2.2. Los recursos ajenos. II.2.2.1. Las cuotas de ingreso y las cuotas periódicas. II.2.2.2. La entrega de bienes para la gestión de la cooperativa y los pagos del socio para la obtención de servicios cooperativos. II.2.2.3. Las participaciones especiales. II.2.2.4. Las obligaciones emitidas. II.2.2.5. Los títulos participativos. II.2.2.6. Las cuentas en participación.-Reflexión final._Bibliografía consultada

\section{INTRODUCCION}

La sociedad cooperativa ocupa un puesto importante como instrumento asociativo voluntario que apunta al equilibrio socio-económico de un mundo en crisis eternizada. Su estabilidad está vinculada a los mecanismos económicos que hoy por hoy representan una de las bases fundamentales para su nacimiento, desarrollo y mantenimiento como empresa solvente, activa y competidora.

Esta realidad tanto influyó en nuestra vocación investigativa que culminó con la identidad del tema de la Tesis Doctoral que escribimos como integrantes del Programa de Doctorado en Derecho de la Universidad de Deusto. Así, dada la calidad de investigadores, intentaremos que este trabajo constituya un ensayo didáctico que proporcione el entendimiento sobre las peculiaridades de la financiación de las sociedades cooperativas como empresas.

Para ello, en el primer apartado, buscamos la comprensión acerca de la sociedad cooperativa como el titular de una organización destinada a la producción o mediación de bienes o servicios para el mercado. Después, en el segundo, desarrollamos un análisis de los artículos que la Ley estatal y que la Legislación vasca reservó a la estructura financiera de la sociedad cooperativa. Aquí hicimos un examen de los recursos propios de financiación, de los recursos ajenos, y una nota especial sobre la especificidad del fondo de educación y promoción. 
Finalmente, en el último apartado, presentamos unas reflexiones derivadas de nuestro estudio.

\section{LA SOCIEDAD COOPERATIVA: GENERALIDADES}

Antes de analizar los contenidos relativos a la financiación cooperativa es conveniente hacer algunas consideraciones iniciales, de tipo general, sobre el concepto de la cooperativa y su encuadramiento como empresario titular de una empresa jurídica reconocida por los mecanismos jurídicos. Comprender la definición de sociedad cooperativa y conocer su perfil de empresario es significativo para entender la importancia de la financiación como medio indispensable para su nacimiento y desarrollo en el mercado.

\section{I.1. El concepto de cooperativa}

Para ofrecer una aproximación al concepto de cooperativa, la mejor opción es recurrir a la Declaración de la Identidad Cooperativa que la Alianza Cooperativa Internacional adoptó en su XXXI Congreso, celebrado en la ciudad de Manchester en septiembre de 1995. En este documento, la $\mathrm{ACl}$ definió la cooperativa como una asociación de personas que se han unido de forma voluntaria para satisfacer sus necesidades y aspiraciones económicas, sociales y culturales en común, mediante una empresa de propiedad conjunta y gestión democrática ${ }^{1}$.

Ya que esa definición pretendió ser una declaración de mínimos², consideramos provechoso enriquecerla con los conceptos apuntados por los tratadistas. Es cierto que el elenco de contribuciones doctrinales es extenso, pero vamos destacar la de Rosembus, que en sentido similar a la definición de la $\mathrm{ACl}$ conceptuó la cooperativa como una entidad basada en la autonomía de voluntad de las personas que la integran para satisfacer sus necesidades económicas, así como las de

\footnotetext{
1 Declaración de la Alianza Cooperativa Internacional sobre la Identidad Cooperativa aprobada en Manchester.

2 Informe sobre la Declaración de la Alianza Cooperativa Internacional sobre la Identidad Cooperativa aprobada en Manchester: esta definición pretende ser una declaración de mínimos; no pretende ser una definición de la cooperativa «perfecta». Es amplia en su alcance, reconociendo que los socios de diferentes tipos de cooperativas estarán involucrados de forma diferente y que esos socios deben organizar sus asuntos.
} 
naturaleza cultural y social, mediante el esfuerzo propio y la ayuda mutua $^{3}$. La del profesor DIVAR, que no considera incompatibles los términos cooperativa y mercantil y, de hecho, define la sociedad cooperativa como una sociedad mercantil que en régimen de empresa comunitaria, y bajo todo objeto social de lícito comercio, se constituye para la equitativa y mutua ayuda entre sus miembros y al servicio de la comunidad $^{4}$. Y, la última, la de CARRASCO, que hace hincapié al reparto de excedentes, al decir que las cooperativas son sociedades participativas de capital variable que se gestionan democráticamente por sus socios y cuyos excedentes (plusvalías o minusvalías) se reparten proporcionalmente a la actividad que con ellas realicen aquellos, destinando una parte de sus beneficios a la consecución de objetivos sociales 5 .

\section{I.2. La cooperativa empresa y la cooperativa empresario}

En una primera perspectiva, quizá la comprensión del concepto de empresa cooperativa pueda resultar confusa, debido a que hasta hace poco tiempo el ánimo de lucro se ha considerado como uno de los elementos definidores de la empresa, entendida como organización para el mercado.

Tradicionalmente se ha identificado mercantilidad y lucro, pero en la actualidad la mercantilidad viene dada por dos notas: la economicidad de la gestión, y la organización.

Esta operación hizo desaparecer el espíritu del lucro como componente indispensable al concepto de empresa y por supuesto prescindible a la adquisición del estado de empresario. Es decir, el requisito de mercantilización de la empresa y del empresario recayó en el ejercicio profesional de la actividad. La muestra de que el ánimo de lucro desapareció como menester esencial de la mercantilidad es comprobable a través del artículo 277 del Código de Comercio vigente, y en el hecho de reputarse mercantiles por razón de la forma a las sociedades anónimas independientemente de que su finalidad sea

\footnotetext{
3 Rosembuj, T.: La Empresa Cooperativa, CEAC, Barcelona, 1982, pág. 9.

4 Divar, J.: Lecciones de derecho mercantil. La Empresa. El empresario Individual. El empresario Social, Universidad de Deusto, Bilbao, 1981, pág. 164.

5 Carrasco Carrasco, M.: La nueva estructura de fondos propios para las cooperativas agroalimentaria; Junta de Andalucía. Consejería de Trabajo. Dirección de Trabajo Asociado y Empleo. Sevilla, 1993.
} 
o no lucrativa ${ }^{6}$. Ello indica que la inexistencia del interés especulativo no es suficiente, por sí misma, para negar mercantilidad a la naturaleza de las instituciones empresariales, ni su presencia es bastante para afirmarla. Por ello, y quebrado el vínculo con el espíritu de lucro, nos parece claro que la empresa es una organización de capital y de trabajo destinada a la producción o a la mediación de bienes o de servicios para el mercado 7 . La empresa es, pues, la forma o modo de actividad.

Con esto, al mismo tiempo en que se liberó de la finalidad del acto mercantil en sí mismo, el Derecho fundamentó la comercialidad a través del dato objetivo y tangible de la organización en forma mercantil $^{8}$. Es decir, la comercialidad de la empresa no está vinculada a la actividad que realiza, sino a la forma, el método o la manera de realizarla. Si la explotación de dicha actividad se hace en relación con el mercado, en forma profesional, organizada y, en definitiva, disponiendo de una empresa y utilizando los métodos mercantiles, no cabe duda que el sujeto que la realiza debe ser considerado empresario mercantil y deberá someterse al estatuto propio de éstos ${ }^{9}$.

Podemos apuntar que la actividad económica es el objetivo para cuya realización se crea una empresa y surge el sujeto peculiar respecto a los demás sujetos de derecho: el empresario. De esta forma, y en la esfera de la actuación empresarial, subrayamos que el desarrollo de la actividad es la razón imperiosa para demostrar la creación de la empresa, y su realización es que otorga al sujeto jurídicamente agente la consideración y el status de empresario mercantil.

Si en el orden jurídico mercantil la empresa es una determinada forma de actividad económica organizada, es obvio que toda empresa necesita un sujeto que organice y ejercite esa actividad. Como hemos dicho anteriormente, ese sujeto es el empresario: persona física o jurídica que por sí o por medio de delegados ejercita y desarrolla en nombre propio una actividad en el mercado constitutiva de empresa, adquiriendo la titularidad de las obligaciones y derechos nacidos de esa actividad $^{10}$.

6 Broseta Pont, M.: La empresa, la unificación del Derecho de obligaciones y el derecho mercantil, Biblioteca Tecnos de Estudios Jurídicos, Madrid, 1965, pág. 238.

7 Broseta Pont, M.: Manual de Derecho mercantil; Tecnos, Madrid, 1981, pág. 88.

8 GADEA, E. (1999): op. cit., pág. 259: v. Nota al pie n. ${ }^{\circ} 28$.

9 Broseta Pont, M. (1965): op. cit. págs. 260 y 261.

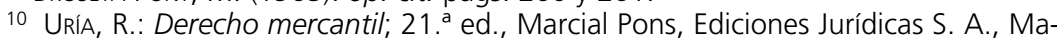
drid, 1994, pág. 36 y 37. 
En la esfera jurídica, al empresario no se le ha exigido el desarrollo de la actividad de manera directa y personal, sino que la actividad debe ser desarrollada por personas encargadas de la gestión empresarial, en su propio nombre. En este sentido, podemos decir que la empresa representa la actividad del empresario.

Esta idea, incluso parece estar presente en el propio Código de Comercio español cuando, en algunos de sus aspectos, denomina "empresa» al objeto a que las sociedades se dediquen (véase el vigente art. 221 y los derogados arts. 117.2 y 122). Pensada la empresa como simple modo o forma de obrar humano, necesariamente habría de conseguir un puesto en el amplio cuadro de la actividad jurídica, en la categoría superior de los actos jurídicos conjuntos de carácter continuado (procesos) que, aun implicando una combinación o serie de actos simples coordinados entre sí por la unidad de acción y de fin, ofrecen en todo momento una visión unitaria del fenómeno ${ }^{11}$.

Así, y en respecto a la empresa cooperativa, debemos subrayar que la sociedad (a manera de las sociedades mercantiles) también desarrolla la explotación de actividad económica en el ámbito del mercado, en forma profesional, organizada y disponiendo de una empresa que utiliza los métodos mercantiles.

Por esto debemos señalar que en puridad técnica la sociedad cooperativa debe ser considerada una fórmula jurídica para la organización económica, sujeta a los principios y fines que le son específicos y que tiene la misma extensión técnica y económica que puede tener una sociedad capitalista (anónima o limitada) ${ }^{12}$. La sociedad cooperativa es, así, titular de los bienes que se configuran como medio para alcanzar su finalidad, es el sujeto que organiza y dirige la empresa.

En definitiva, la cooperativa es un tipo de empresario social, un ente dotado de personalidad jurídica, titular del ejercicio de una actividad económica ${ }^{13}$. Es decir, la cooperativa es que reviste el desarrollo de las actividades económicas y sociales, mientras que los administradores son responsables por su buen funcionamiento. Los socios de

11 Id., ob. cit., pág. 38.

12 DivAR, J.: La alternativa cooperativa; Barcelona, 1985.

13 Morillas Jarillo, M.J. y Feliú ReY, M.I.: Curso de cooperativas; Tecnos, Madrid, 2002, pág. 71. 
la empresa cooperativa, adjudican los riesgos, aportan los fondos necesarios para su constitución, emprenden, modernizan y por tanto, asumen el compromiso de la producción y participación democrática del proceso de toma de decisiones.

\section{LA FINANCIACION DE LAS SOCIEDADES COOPERATIVAS}

Después de explicar que la cooperativa es el empresario titular de la empresa, buscaremos desarrollar en este epígrafe el objeto específico del trabajo. Para ello analizaremos las peculiaridades relativas a la financiación de las sociedades cooperativas reguladas por la legislación estatal y por la autonómica del País vasco.

\section{1. Planteamiento general}

De entre los medios necesarios para el desarrollo de una actividad empresarial equilibrada y racional, una financiación adecuada es imprescindible para mantener la empresa con alto nivel de competitividad en el mercado.

El arquetipo societario cooperativo en cuanto que soporte de las actividades empresariales desarrolladas en su seno para el cumplimiento del objeto social perseguido, necesita de un conjunto de normas que permitan vehicular todo tipo de operaciones entre los socios y la entidad, así como entre ésta y los terceros. A esta exigencia responden a la postre los diversos regímenes económicos que en cada una de las leyes cooperativas se proponen ${ }^{14}$.

Verificada su peculiaridad económica, no exageramos al decir que la financiación corresponde al procedimiento monetario realizado para movilizar recursos. Su aspecto general consiste en buscar los fondos necesarios para realización de los objetivos para los cuales la cooperativa fue creada. Por ello, encontramos en las cooperativas una búsqueda cada vez más intensa de una estructura financiera eficaz que les permita emplear los mismos instrumentos disponibles para otros tipos de empresa.

14 Prieto JuÁrez, J.A.: El régimen económico en la vigente legislación cooperativa a la luz de los principios proclamados por la alianza cooperativa internacional en 1995; AECOOP - EEC, REVESCO, n. 77, Madrid, 2002, pág. 133. 
Este aspecto es clave para la expansión de las cooperativas, para alcanzar una dimensión que les permita competir adecuadamente ${ }^{15}$.

Siguiendo este planteamiento, la vigente legislación española en materia de cooperativas proyectó la necesidad de reforzar la consolidación empresarial de estas entidades, para lo que ha sido preciso flexibilizar su régimen económico y societario y acoger novedades en materia de financiación empresarial' ${ }^{16}$.

En Euskadi, el legislador amoldó la vigente regulación a las necesidades de los emprendedores y de los proyectos empresariales que surgen, facilitando la constitución de nuevas cooperativas y consolidando, con perfeccionamientos técnicos y arreglos precisos, las cooperativas ya existentes en el País Vasco. En los comienzos de la década de los noventa, los legisladores de la Comunidad Autónoma vasca culminaron un proceso renovador de la legislación cooperativa, elaborando un texto legal de importancia y perfección indiscutible. Con la Ley 4/1993 de Euskadi, la intención fue responder, como quedaron respondidas, las entonces actuales carencias del marco jurídico del cooperativismo vasco. En la medida que la Ley atendió a las nuevas regulaciones advenidas de la incorporación del Estado a la Comunidad Económica Europea, fueron introducidos avances e instrumentos jurídicos desarrollados tanto en el Derecho interno como en el comparado ${ }^{17}$. El texto legislativo de Euskadi favorece la exigencia de nuevas aportaciones tanto obligatorias como voluntarias y se prevén nuevas fórmulas de financiación como las aportaciones especiales y los títulos participativos. También merece mención especial la preocupación que muestra a la hora de regular las medidas de protección en garantía de terceros, fundamentalmente a través del sistema de imputación de pérdidas y de la exigencia de mantener la cuantía correspondiente a la aportación obligatoria fijada para adquirir la condición de socio ${ }^{18}$.

Así, debemos anotar que comparados los dos textos legislativos, y observada la anterioridad en la edición de la Ley vasca de cooperativas respecto a la Ley estatal, podemos decir que aquella sirvió de fuente

15 Gómez Urquijo, L. y De los Ríos Añón, M.: Respuestas a las dificultades de captación de capital en las cooperativas: el caso de Eroski; Anuario de Estudios Cooperativos, Universidad de Deusto, Bilbao, 1997, pág. 214.

16 Exposición Motivos, Ley 27/1999, de 16 de julio, de Cooperativas.

17 EUSKADI. Ley 4/1993, de 24 de junio. Exposición de motivos.

18 GADEA, E.: pág. 201, op. cit. pág. 12. 
modernizadora de ésta, visto que la legislación autonómica acentuó con anticipación el interés legislativo por el fortalecimiento empresarial de la sociedad cooperativa.

De un modo general, la determinación de la Ley estatal, relativa al régimen económico cooperativo, es idéntica a la autonómica. Las diferencias son singulares y observadas sobremanera con posterioridad a la edición de la Ley 1/2000, de 29 de junio. Esta Ley introdujo las aportaciones financieras subordinadas, para allegar financiación fundamentalmente externa — sin olvidar la interna - con carácter de permanencia que integre los recursos propios de la cooperativa (considerándose capital social), sujetas a las condiciones que establezcan.

\section{II.2. Las estructura financiera de la sociedad cooperativa}

Hemos visto que la empresa cooperativa se asienta como organización de capital y de trabajo destinada a la producción o a la mediación de bienes o de servicios para el mercado. Ahora, importa la comprensión de la estructura relativa a los recursos financieros necesarios para el desarrollo de su infraestructura y el ejercicio de actividades en un mercado de competencia, de forma que se hagan compatibles los principios y valores cooperativos con la rentabilidad y el éxito del proyecto empresarial que se pone en marcha bajo la forma de sociedad cooperativa ${ }^{19}$. Por esto, es conveniente la comprensión de los fondos propios y ajenos que componen la estructura financiera de la empresa cooperativa.

\section{II.2.1. Los fondos propios}

En términos generales, los recursos propios representan aquella parte de la financiación básica de la empresa cuya función es la cobertura de los riesgos derivados de la gestión ${ }^{20}$. Del análisis de los dos textos que integran nuestro estudio se deduce que la sociedad cooperativa se beneficia de los siguientes recursos propios: el capital social formado por las aportaciones de los socios y los excedentes no repartidos que integrarán los fondos sociales.

19 Morillas Jarillo, M.J. y Feliú Rey, M.I.: op. cit., pág. 357.

20 Del Pozo, F.: El fortalecimiento de recursos propios; Marcial Pons, Zaragoza, 1992. 


\section{II.2.1.1. EL CAPITAL SOCIAL}

La noción de capital social es ambigua por la multiplicidad de conceptos que expresa. No obstante, el capital social de la sociedad cooperativa - como de las sociedades en general- es siempre y en todo caso una cifra del pasivo que expresa el valor de los fondos propios de una determinada procedencia: las aportaciones de los socios ${ }^{21}$. Esa definición se recoge tanto en la legislación estatal como la vasca, visto que ambas coinciden que el capital social es constituido por las aportaciones de los socios, sean obligatorias o voluntarias. Las aportaciones al capital, tanto las obligatorias como las voluntarias, podrán ser efectuadas en dinero, o en bienes o derechos cuyo valor será fijado por los administradores, previo informe de al menos un experto. Para estos casos es imprescindible la autorización por los Estatutos y aprobación por la Asamblea General.

La documentación de acreditación de las aportaciones no ha sido regulada por el legislador estatal22. A su paso, el legislador vasco hizo previsión expresa acerca de tal temática, determinando por el artículo 57.2 que las aportaciones al capital social se acreditarán mediante títulos nominativos que no tendrán la consideración de títulos de valores, o mediante libretas o cartillas de participación.

Ambas las legislaciones establecen el principio general de limitación de participación en el capital social y determinan que las aportaciones de un socio en las cooperativas de primer grado no podrán exceder a un tercio del capital. Este límite queda exceptuado por la Ley estatal a los casos en que se trate de sociedades cooperativas, entidades sin ánimo de lucro o sociedades participadas mayoritariamente por cooperativas ${ }^{23}$; y por la Ley vasca en los casos de socios colaboradores y en las cooperativas compuestas por menos de diez socios ${ }^{24}$.

Entre los elementos que componen el patrimonio de la cooperativa, las aportaciones de los socios al capital constituyen el primer recurso en el tiempo y principal por su importancia, sobre todo por su

21 GADEA, E.: Derecho de las cooperativas: análisis de la Ley 4/1993, de 24 de junio, de cooperativas del País Vasco; 2. ${ }^{a}$ ed., Universidad de Deusto, Bilbao, 2001, págs. 204, en citación de Vicent F. (nota al pie n. ${ }^{\circ}$ 272).

22 Razón por la cual Los Estatutos deben prever como medida de precaución.

23 España. Ley 27/1999, de Cooperativas, Art. 45.6.

24 EuSKADI. Ley 4/1993, de Cooperativas, Art. 57.4, observada la modificación introducida por la Ley $1 / 2000$. 
trascendencia jurídica. Las aportaciones sociales, una vez que ingresan en el patrimonio cooperativo y configuran la cifra de capital social, constituyen un recurso propio de la cooperativa en el ejercicio de su actividad económica, pues, aunque el socio al separarse de la cooperativa puede exigir la restitución de sus aportaciones, ello no significa que éstas no sean de riesgo, ya que, antes de retirarlas, se le deducirán las pérdidas que le sean atribuibles, y además mantendrá su responsabilidad durante varios años, por el importe de la suma reembolsada ${ }^{25}$.

\section{a) Las aportaciones obligatorias}

Las aportaciones obligatorias son fijadas por los estatutos como las contribuciones mínimas al capital social para ser socio, que podrá ser diferente para las distintas clases de socios o para cada socio en proporción al compromiso o uso potencial que cada uno de ellos asuma de la actividad cooperativizada ${ }^{26}$. Una y otra legislación coincide que los estatutos fijarán la aportación inicial para la condición de socio ${ }^{27}$. La exigencia de una aportación mínima es importante en tanto dicha cuantía será fijada de manera que el conjunto de las aportaciones obligatorias formen un importe de capital conveniente para la empresa. Para facilitar la adecuación entre la cifra de capital y el nivel de riesgo de la empresa, las dos legislaciones permiten que los Estatutos determinen aportaciones diferentes para las distintas clases de socios o para cada socio, en simetría al encargo o uso potencial que cada uno de ellos asuma de la actividad cooperativa. No obstante, las dos legislaciones autorizan que, con posteridad al ingreso del socio en la cooperativa se le puedan exigir nuevas aportaciones obligatorias en cuantía que será fijada de acuerdo con los criterios señalados anteriormente. La disconformidad del socio no le otorga otra alternativa que la baja de la empresa, que será considerada justificada.

Los socios deberán desembolsar, al menos, en un veinticinco por ciento en el momento de la suscripción y la cantidad restante en el

25 Fajardo García, I.G.: en pág 23 de op. cit. Pág. 29.

26 España. Ley 27/1999, de Cooperativas, Art. 46.1 y EusKAdI. Ley 4/1993, de Cooperativas, Art. 59.1 y 59.2 .

27 Reglamentación del Art. 46.1 de la Ley estatal y 58.1 de la legislación del País Vasco. 
período ajustado por los Estatutos o por la Asamblea General ${ }^{28}$. El socio que no cumpla con el desembolso que le queda en el plazo ajustado, incurrirá en mora que será compensada mediante el pagamiento del interés legal y la sociedad será resarcida por los perjuicios resultantes de la morosidad. La falta de regularización del estado de mora podrá implicar en baja obligatoria o expulsión de la cooperativa, según el caso ${ }^{29}$.

En los casos en que la comprobación de pérdidas de la cooperativa a los socios resultara en disminución de la proporción de la aportación al capital —relativa al importe fijado-, el socio afectado deberá complementar la aportación inmediatamente al requerimiento del Consejo Rector, que fijará un plazo de entre dos meses hasta un año.

\section{b) Las aportaciones voluntarias}

Las aportaciones voluntarias admiten a la sociedad la obtención de recursos propios sin acordar nuevas aportaciones obligatorias. No son necesarias para la adquisición ni para la conservación de la condición de socio en la sociedad cooperativa, pero coinciden con las obligatorias en el hecho de que después de que el socio asume el compromiso de desembolsarlas, su compromiso tiene naturaleza social y en que, al igual que aquéllas, integran el capital social. Son por tanto aportaciones sociales comprometidas totalmente con el riesgo de la empresa $^{30}$ y pueden ser utilizadas para auxiliar a la satisfacción de las deudas de la cooperativa.

Este tipo de aportaciones no dependen única y meramente de la voluntad del cooperativista. Para que sean aceptadas deben estar previstas en los Estatutos y se requiere acuerdo de la Asamblea General o del Consejo Rector ${ }^{31}$. Mientras la Ley estatal determina que las aportaciones voluntarias deberán desembolsarse totalmente en el momento de la suscripción (art. 47.2), la legislación del País Vasco ha sido más

28 El desembolso mínimo de las aportaciones obligatorias es determinado en la Ley estatal a través del Art. 46.3. y en la Ley vasca por el Art. 58.2.

29 Sobre la mora en el desembolso: Ley estatal Art. 46.5 y Ley de Euskadi Art. 58.5: A los socios morosos se les incumbe, también, la obligación de resarcir la cooperativa, en su caso, de los daños y perjuicios causados por la morosidad.

30 PAStOR Sempre, C.: «El régimen económico: principales aspectos», in: La sociedad cooperativa en la ley 27/1999, de 16 de julio de Cooperativas; Comares, Granada, 2001. Coordinado por Francisco J. Alonso Espinosa.

31 España, Ley 27/1999, de Cooperativas, Art. 47.1 y EusKADI, Ley 4/1993, Art. 59.1. 
flexible, dado que otorgó a la Asamblea General cierta libertad para fijar las condiciones de las mismas. Dichas condiciones comprenden el plazo de suscripción, el plazo para el desembolso y el tipo de interés al que se abonaran estas aportaciones.

\section{c) La transmisión y el reembolso de las aportaciones}

El vínculo creado entre el socio y la sociedad impone que las aportaciones solamente sean transferibles a otros socios o a las personas que se vean interesadas a participar de la consecución del fin social en la forma establecida por los Estatutos. De esta forma podemos decir que ambas las legislaciones estudiadas permiten ${ }^{32}$ que las aportaciones sean transferidas tanto por acto inter vivos como por sucesión causa mortis ${ }^{33}$. A la primera posibilidad la Ley estatal exige que el adquiriente sea socio de la cooperativa o, no lo siendo, adquiera la calidad de socio en el plazo no superior a los tres meses siguientes a la transmisión. En relación a la segunda, los causa-habientes, si son socios, podrán adquirir las aportaciones del causante. Si, por casualidad, los causa-habientes no son socios, podrán solicitar esta condición en el plazo de seis meses desde el fallecimiento.

Debemos expresar, también, que las aportaciones al capital social son reembolsables en caso de baja de la cooperativa. Hemos observado que genéricamente, en las dos legislaciones, la liquidación de las aportaciones se hará según el balance de cierre del ejercicio correspondiente a la época de la baja. El reembolso de las aportaciones al capital social será integral, con excepción de los casos que reclamen deducciones provocadas por pérdidas o por baja no justificada por incumplimiento del período de permanencia mínimo ${ }^{34}$. El plazo para el reembolso de las aportaciones al capital social es idéntico en las dos legislaciones, y no podrá exceder cinco años contados desde la fecha de la baja, mientras que resultando el reembolso de fallecimiento de socio, el plazo de la restitución a los causa-habientes será de un año, contado desde la fecha del hecho causante.

32 El artículo 50.a) de la Ley 27/1999 aun establece que en todo caso habrá de respetarse el límite impuesto en el artículo 45.6., mientras que el b) esclarece que en otro caso, tendrán derecho a la liquidación del crédito correspondiente a la aportación.

33 El artículo 60.2, de la Ley 4/1993, explica que la admisión está condicionada a lo dispuesto en el artículo 20.

34 Ley estatal, Art. 51 y Ley vasca, Art. 63. 


\section{d) La actualización de las aportaciones}

La actualización de las aportaciones constituye un elemento peculiar de las sociedades cooperativas. Decimos esto dada la particularidad de este tipo societario, donde los socios gozan solamente del derecho de restitución o reembolso de la importancia aportada a la empresa y no una parcela de patrimonio. Por esta razón, el legislador otorgó a los socios, a través de la actualización de las aportaciones, el beneplácito de recibir, en caso de reembolso, una cantidad semejante a la inicial. La actualización, entonces, es el medio que la propia sociedad emplea para mantener actualizada la inversión del socio.

Para que pueda ser realizada la actualización de las aportaciones, las Leyes estudiadas armonizan su entendimiento de que es necesario que se regularice el balance de la cooperativa. Dicho balance, que podrá ser regularizado en los mismos términos de las sociedades de Derecho común ${ }^{35}$, se realiza mediante la aplicación de un coeficiente al valor de adquisición de los diferentes componentes del inmovilizado. Esto posibilita la obtención de una plusvalía por la diferencia del valor inmovilizado después de la actualización y el valor inmovilizado contabilizado que se hace aflorar en los recursos propios de la sociedad ${ }^{36}$. Sobre este particular, FeRnÁndez GuAdAÑo dijo que la finalidad de la regularización de balances es corregir los efectos de la inflación sobre el inmovilizado, y que la actualización de aportaciones es una fuente de financiación propia e interna ${ }^{37}$.

En respecto a la plusvalía, debemos subrayar que mientras el artículo 49.2 de la Ley estatal determina que se destinará a la actualización del valor de las aportaciones al capital social de los socios o al incremento de los fondos de reserva, obligatorios o voluntarios, en la proporción que se estime conveniente; el artículo 61.2, de la Ley vasca establece que se destinará por la cooperativa, en uno o más ejercicio, a la actualización del capital o al incremento de las reservas, obligatorias o voluntarias, en la proporción que aquélla estime conveniente. No obstante, debemos resaltar que ambas las legislaciones orientan en el sentido de que cuando la cooperativa tenga pérdidas, el destino primero de la plusvalía será la compensación de las mismas, y el resto a los destinos que hemos señalado anteriormente.

35 España, Ley 27/1999, de Cooperativas, Art. 49.1 y EusKADI, Ley 4/1993, Art. 61.1.

36 GADEA, E.: Derecho de las cooperativas, op. cit., pág. 214.

37 Fernández Guadaño, J.: pág. 10, op. cit., pág. 20. 


\section{II.2.1.2. LOS EXCEDENTES NO REPARTIDOS}

Finalizado el ejercicio económico, donde la cooperativa efectúa las actividades económicas, se hacen los análisis del significado económico de las operaciones ejecutadas por la sociedad y se determina el resultado. En las cooperativas reguladas por la Ley estatal los resultados serán llevados a cabo conforme a la normativa general contable ${ }^{38}$, mientras que en aquellas disciplinadas por la Ley vasca serán aplicados de acuerdo con las normas y criterios establecidos para las sociedades mercantiles ${ }^{39}$.

\section{a) Determinación de los excedentes}

Dicho esto, subrayamos que la aplicación de los excedentes está predeterminada en las leyes de diversa forma y cuantía. En la Ley estatal, el artículo 58.2 establece que después de la deducción de las pérdidas y antes de la consideración del Impuesto de Sociedad, el resultado cooperativo será destinado en proporción de veinte por ciento al fondo de reserva obligatorio y cinco por ciento al fondo de educación y promoción. En el 58.3, la legislación general determina que los excedentes y beneficios extracooperativos y extraordinarios disponibles, una vez satisfechos los impuestos exigibles, se aplicarán, conforme establezcan los Estatutos o acuerde la Asamblea General en cada ejercicio, a dotación de fondos de reserva voluntarios.

El artículo 67, 1 y 2 de la Ley de Euskadi, determina que una vez deducidos los valores relativos a compensar pérdidas de ejercicios anteriores y a atender los impuestos exigibles, los excedentes serán destinados en una cuantía de veinte por ciento al fondo de reserva obligatorio y diez por ciento al fondo de educación y promoción cooperativa. Sin embargo, mientras el valor de los excedentes no alcancen un importe igual a cincuenta por ciento del capital social, el porcentual destinado al fundo de educación y promoción podrá ser rebajado a la mitad, aplicándose el restante al fondo de reserva obligatorio. El resto estará a disposición de la Asamblea General, que podrá distribuirlo en la forma siguiente: retorno a los socios, dotación a fondos de reserva voluntarios, con el carácter irrepartible o repartible que establezcan los Estatutos o, en su defecto, la Asamblea General,

38 España, Ley 27/1999, de Cooperativas, Art. 57.2.

39 EUSKADI, Ley 4/1993, Art. 66.1. 
y, en su caso, participación de los trabajadores asalariados en los resultados de la cooperativa ${ }^{40}$.

Aquí debemos abrir un paréntesis para afirmar que a diferencia del fondo de reserva obligatorio, el fondo de educación y promoción está adscrito a una función concreta. Su destino es fomentar el principio cooperativo de educación, formación e información de los socios, a través del desarrollo de todas las actividades fijadas por los Estatuto o la Asamblea General y que cumplan con los propósitos formativos y culturales que recogen en las Leyes. Podríamos clasificarlo como fondo mixto, dado que es formado por recursos tanto internos de la sociedad cooperativa, como otros ajenos a ella. Esta condición también se puede decir del fondo de reserva obligatorio, una vez que se nutre de otras partidas distintas a los excedentes, pero no parece acertado porque, aunque se deba mencionar los otros recursos, lo cierto es que los fondos obligatorios se sostienen básica y principalmente de excedentes no repartidos.

\section{b) El fondo de reserva obligatorio}

Este fondo es una de las más importantes cuentas de pasivo de la empresa.

El fondo de reserva obligatorio, equivalente a la reserva legal de la sociedad anónima, tiene gran importancia en una sociedad de capital variable como la cooperativa, ya que su estabilidad favorece la conservación y el desarrollo de las actividades empresariales de la cooperativa. Como medida orientadora debemos anotar la finalidad de garantía del fondo de reserva obligatorio, puesto que con la reserva obligatoria deberán compensarse las pérdidas si no existen otras reservas disponibles $^{41}$. De este modo, observamos que dicho fondo tiene la importante función de fortalecer el grado de la financiación de la sociedad cooperativa, mediante el incremento de su solvencia financiera.

Estas ideas se reflejan tanto en la Ley estatal como en la vasca, cuando dicen que el fondo de reserva obligatorio destinado a la consolidación, desarrollo y garantía de la cooperativa, es irrepartible entre los socios ${ }^{42}$. Mientras la legislación general indica que a los fondos de

40 EUSKADI, Ley 4/1993, de 24 de junio, Art. 67.2.a e $b$.

41 GadeA, E.: pág. 227, op. cit. Pág. 19.

42 España, Ley 27/1999, de Cooperativas, Art. 55.1 y EusKAdı, Ley 4/1993, Art. 68.1. 
reserva obligatorio se destinarán obligatoriamente: los porcentajes de excedentes cooperativos y de los beneficios extracooperativos y extraordinarios que establezcan los Estatutos o fije la Asamblea General, las deducciones sobre las aportaciones obligatorias al capital social en la baja no justificada de socios y las cuotas de ingreso de los socios cuando estén previstas en los Estatutos o las establezca la Asamblea General; la vasca define que se destinarán obligatoriamente al fondo de reserva obligatorio el porcentaje de los excedentes disponibles que establezca la Asamblea General, las deducciones sobre las aportaciones obligatorias al capital social en caso de baja de socios y las cuotas de ingreso.

\section{c) Los fondos de reserva voluntarios ${ }^{43}$}

Consideramos estos fondos como recursos propios porque todos los recursos que los completan son generados por la propia sociedad cooperativa a través de recursos no distribuidos. Tienen la finalidad de aumentar la capacidad financiera de la empresa y dependen de previsión estatutaria o acuerdo en Asamblea General.

Es conveniente registrar que el artículo 57.5 de la Ley estatal prevé que las cooperativas podrán crear una reserva estatutaria irrepartible a la que se destinarán el resto de resultados positivos y cuya finalidad será necesariamente la reinversión en la consolidación y mejora de los servicios de la cooperativa y a la que se le podrán imputar la totalidad de las pérdidas conforme a lo establecido en el artículo 59.2.a. También las cooperativas del País Vasco podrán compensar las pérdidas mediante la imputación de su totalidad a los fondos de reserva voluntario, si existieren ${ }^{44}$.

\subsubsection{Los recursos ajenos}

Los recursos ajenos, o fondos externos, para la financiación de la sociedad cooperativa, como su nombre indica, son los fondos que la empresa cooperativa recibe de terceros, no miembros de la cooperativa, o bien, si no son miembros, no se incorporan al capital social ${ }^{45}$. Las fuentes de financiación externa son identificadas bajo los siguientes rótulos: a) Las cuotas de ingreso y las cuotas periódicas, b) La entrega

\footnotetext{
43 Ley 27/1999, de Cooperativas, Art. 58.3. y 59.2.a).

44 EUSKADI, Ley 4/1993, Art. 69.2.a.

45 Para Grávalos Gastaminza, M. ${ }^{a}$ A.: op. cit., pág. 130.
} 
de bienes para la gestión de la cooperativa y los pagos del socio para la obtención de servicios cooperativos, c) Las participaciones especiales, d) Las obligaciones emitidas, e) Los títulos participativos y f) las cuentas en participación.

\section{II.2.2.1. LAS CUOTAS DE INGRESO Y LAS CUOTAS PERIÓDICAS}

Se pueden definir las cuotas de ingreso como el desembolso añadido, respecto al importe que se estableció como aportación obligatoria mínima al capital social, exigida a los nuevos socios como medida de explotación para evitar o, al menos, mitigar el «efecto dilución» o disminución del coeficiente patrimonio neto/socio ${ }^{46}$. La cuantía de estas cuotas no podrá ser superior al veinticinco por ciento del valor de la aportación al capital social que se le exija al socio para el ingreso en la cooperativa ${ }^{47}$.

Las cuotas periódicas son las aportaciones que realizan los socios de la cooperativa para atender a los gastos que en cada caso se acuerde, que pueden ser de los más variados: pueden utilizarse tanto para cubrir gastos ordinarios de un ejercicio (por ejemplo, el pago del alquiler de un local) como para sufragar las inversiones necesarias para desarrollar el objeto social (por ejemplo, el pago de la cuota de un préstamo solicitado para al adquisición de maquinaria ${ }^{48}$.

Tanto las cuotas de ingreso como las periódicas podrán ser diferentes para las distintas clases de socios, o en función de la naturaleza física o jurídica de los mismos, o para cada socio en proporción a su respectivo compromiso o uso potencial de la actividad cooperativa ${ }^{49}$. En uno y otro caso pueden ser fijadas por los Estatutos o por la Asamblea General y, no integran el capital social ni serán reintegrables.

\section{II.2.2.2. LA ENTREGA DE BIENES PARA LA GESTIÓN DE LA COOPERATIVA Y LOS PAGOS DEL SOCIO PARA LA OBTENCIÓN DE SERVICIOS COOPERATIVOS}

La entrega de bienes, la prestación de servicios y los pagos realizados a la cooperativa (cuyas condiciones de contratación deberán estar

46 GAdeA, E.: Derecho de las cooperativas: análisis de la Ley 4/1993, de 24 de junio, de cooperativas del País Vasco; 2. ${ }^{a}$ ED., Universidad de Deusto, Bilbao, 2001, pág. 218.

47 EsPaña, Ley 27/1999, Art. 52.2 y EusKADI, Ley 4/1994, Art. 65.2.

48 GAdEA, E.: op. cit, pág. 219.

49 España, Ley 27/1999, Art. 52.1 y EuSKAdI, Ley 4/1994, Art. 65.1. 
fijadas en los Estatutos), constituyen recursos ajenos que no integran el capital ni el patrimonio de la cooperativa y no podrán ser confiscados por sus acreedores, pero podrán ser exigidos por los acreedores de los socios, en tanto la cooperativa o terceros no hayan adquirido derechos sobre los mismos ${ }^{50}$.

\section{II.2.2.3. LAS PARTICIPACIONES ESPECIALES}

Las participaciones especiales ${ }^{51}$ son recursos financieros obtenidos de la emisión en serie de títulos que podrán ser adquiridos tanto por los socios como por terceros. Son documentos (que pueden ser representados por medio de títulos nominativos) transmisibles libremente que no responden a los condicionamientos atribuidos a las aportaciones de los socios al capital social y, por lo tanto, no otorgan derechos de voto ni conceden a los adquirientes el derecho de participación en la gestión de la cooperativa.

En las cooperativas reguladas por la Ley vasca, dichas participaciones fueron implantadas a través de la Ley $1 / 2000$, cuando se observó el interés del legislador de aproximar la financiación básicamente externa con vistas a su integración al capital social de la sociedad cooperativa. Con esto, la Ley vasca definió que serán participaciones especiales: las financiaciones subordinadas expresamente acogidas a la regulación establecida en este artículo, en las que los suscritores sean necesariamente entidades no cooperativas, el reembolso no tenga lugar hasta que transcurran al menos cinco años desde la emisión y la remuneración se establezca en función de los resultados de la cooperativa; las restantes características de estas participaciones serán establecidas libremente en el momento de su emisión, sin que en ningún caso atribuyan derechos de voto en la Asamblea General ni de participación en el órgano de administración. En relación a la emisión o contratación de las participaciones especiales, el legislador del País Vasco dijo que deberán ser ofrecidas, en cuantía no inferior al cincuenta por ciento, a los socios y trabajadores asalariados de la cooperativa antes de ofrecer a terceros. Tal oferta tendrá publicidad equivalente a la

50 En la Ley 27/1999, de Cooperativas, Art. 52.3, mientras que en la Ley 4/1193, Art. 65.3.

51 Ley 27/1999, de Cooperativas, Art. 53.1., 53.2., y 53.3. 
establecida en la cooperativa para la convocatoria de las Asambleas Generales ${ }^{52}$.

Para ello, la Ley modificativa introdujo las aportaciones financieras subordinadas mediante la adición de un nuevo número 5 al Art. 57 de La Ley originaria. Dichas aportaciones corresponden a la colaboración económica recibida por la cooperativa que, a consecuencia de preferencia para exigibilidad de los colaboradores están situadas después de todos los acreedores comunes. Las aportaciones o financiaciones subordinadas podrán ser aplicables a todas las cooperativas, con excepción de las cooperativas de crédito y de seguros, que sólo podrán serlo cuando no sea impedida por normas básicas específicas para ellas. Por fuerza de la modificación que introdujo el artículo noveno, de la Ley 1/2000, el artículo 64.1, de la Ley 4/1993 pasó a definir las participaciones especiales como las financiaciones subordinadas. Con excepción de la regla general que especificó que para el reembolso no tenga lugar hasta que transcurran el mínimo de cinco años desde la emisión y la remuneración se establezca en función de los resultados de la sociedad, las características restantes de las participaciones especiales serán ajustadas libremente en al momento de su emisión.

\section{II.2.2.4. LAS OBLIGACIONES EMITIDAS}

Las sociedades cooperativas, por acuerdo de la Asamblea General, podrán emitir obligaciones ${ }^{53}$ conforme a lo dispuesto en la legislación aplicable. Como títulos-valores, dichas obligaciones representan la parte de un crédito concedido a la cooperativa y, se trata de títulos que pueden ser nominativos o al portador, que dan derecho a recibir una renta anual en forma de intereses y que llegado el momento de su amortización dan derecho a recuperar toda la inversión ${ }^{54}$. En el caso de que sean los socios que adquieran los títulos emitidos por su

52 Euskadi. Ley 1/2000, de 29 de junio, de modificación de la Ley de Cooperativas del País Vasco.

Artículo noveno. 1. Se da nueva redacción al art. 64 de la Ley 4/1993, de 24 de junio, de Cooperativas de Euskadi (...)

53 Ley general Art. 54.1 y Ley vasca Art. 65.4.

54 SUÁREZ SUÁREZ, A. S.: Decisiones óptimas de inversión y financiación en la empresa; Pirámide, Madrid, 1995, pág. 344, en citación de Fernández Guadaño, J.: La nueva estructura financiera de acuerdo con la Ley 27/1999, de cooperativas; REVESCO, REC, Núm. 77, Madrid, 2002, pág. 20 
propia empresa se trataría de un caso más de financiación voluntaria por parte de los socios que no integran el capital social ${ }^{55}$.

\section{II.2.2.5. LOS TÍTULOS PARTICIPATIVOS}

Con respecto a los títulos participativos, la Ley estatal los compara a los valores mobiliarios y les otorga el derecho a la remuneración que debe ser establecida en el momento de la emisión, y que deberá estar en función de la evolución de la actividad de la cooperativa, pudiendo, además, incorporar un interés fijo ${ }^{56}$. La Ley vasca reguló estos títulos a través de su artículo 65.5, donde les concedió una remuneración mixta en forma de interés fijo más la parte variable establecida en el momento de la emisión, en función de los resultados de la cooperativa.

Podemos, aun, decir que los títulos participativos aportan a sus titulares una serie de derechos, a cambio de la aportación económica, temporalmente predeterminada, que realizan a la sociedad ${ }^{57}$. Quizá por esto, muchos comprenden que estos títulos deterioran la filosofía social de la empresa cooperativa, ya que una parte o la totalidad de la remuneración que obtienen los inversores en títulos participativos depende de los resultados de la sociedad.

\section{I.2.2.6. LAS CUENTAS DE PARTICIPACIÓN}

Las cuentas de participación ${ }^{58}$, reguladas por el artículo 239 del Código de Comercio ${ }^{59}$, pueden ser ventajosas no sólo en cuanto a participación de capital social de un inversor a una cooperativa, sino también en relación a la formalización de convenio de cooperación entre sociedades cooperativas en el que una de las partes alcanza recursos y la otra hace la gestión, compartiendo los resultados. Ambas las legislaciones las adoptan como una fuente alternativa de financiación y son respectivamente reguladas por el artículo 54. 3 de la legislación estatal y 65.6, de la autonómica.

\footnotetext{
55 Fernández Guadaño, J.: pág. 23, op. cit., pág. 20.

56 Ley 27/1999, de Cooperativas, Art. 54.2.

57 Morillas Jarillo, M.J. y Feliú Rey: pág. 412, op. cit., pág 10.

58 Ley 27/1999, de Cooperativas, Art. 54.3.

59 Código de Comercio y Leyes Complementarias; Civitas, Madrid, 1999, Título II, artículo 239: Podrán los comerciantes interesarse los unos en las operaciones de los otros, contribuyendo para ellas con la parte de capital que convinieren y haciéndose partícipes de sus resultados prósperos o adversos en la proporción que determinen.
} 


\section{REFLEXION FINAL}

La sociedad cooperativa comprende una asociación voluntaria y democrática de personas que buscan en conjunto satisfacer necesidades comunes. Sin embargo, anotamos que el éxito de la sociedad cooperativa, como organización empresarial, está subrogado a la captación de recursos financieros que le otorguen los medios indispensables al desarrollo de sus actividades y distribución de los objetivos inherentes a su constitución.

Dada la importancia socio-económica de la cooperativa, el legislador estatal y autonómico vasco ${ }^{60}$ buscó mecanismos suficientes para la captación de recursos económicos que favorezcan la estabilidad económica de la sociedad cooperativa, puesto que la financiación desempeña un papel fundamental para la consecución de un alto nivel de eficiencia en el ámbito empresaria|61.

La previsión de nuevas fórmulas de financiación, como las participaciones especiales y subordinadas, los títulos participativos o las cuentas en participación, junto con la nueva regulación de las ya existentes, como las aportaciones obligatorias y voluntarias, tienen por objeto fomentar el desarrollo del cooperativismo y de su instrumento que no es otro que la sociedad cooperativa.

Así, las novedades introducidas en las legislaciones específicas buscan implementar el desarrollo, la utilidad y seguridad de la sociedad cooperativa. La naturaleza de los mecanismos financieros puede ser objeto de debate de los expertos, pero no materia de desvirtuación de la naturaleza de la cooperativa.

La preservación del espíritu del cooperativismo es de todos, legisladores, investigadores, profesores, abogados, y en última instancia, es cuestión interna de cada empresa cooperativa y responsabilidad de los socios que deben buscar personalmente, de forma incansable e imparable, la compatibilización de los recursos financieros con los principios y valores que sustentan un cooperativismo honorable, eficiente e incuestionable.

60 Cuya anterioridad profiláctica justificamos, quizá, por los principios de la cultura cooperativa de natos en el territorio de Euskadi.

61 Sommerhoff R.W.: Financiamiento cooperativo; Intercoop, Buenos Aires, 1972. 


\section{BIBLIOGRAFIA CONSULTADA}

ArCo Alvarez, J. L.: Régimen económico de las cooperativas españolas; REVESCO, 1970.

BalAy, E.: Bases del Ordenamiento cooperativo de la economía social; Buenos Aires, 1965.

BRoseta Pont, M.: La empresa, la unificación del Derecho de obligaciones y el Derecho Mercantil; Biblioteca Tecnos de Estudios Jurídicos, Madrid, 1965. - Manual de Derecho mercantil, Tecnos, Madrid, 1981.

Buendía Martínez, I.: La integración comercial de las cooperativas; Colección Estudios, CES, Madrid, 1999.

Carrasco Carrasco, M.: La nueva estructura de fondos propios para las cooperativas agroalimentarias; Junta de Andalucía. Consejería de Trabajo. Dirección de Trabajo Asociado y Empleo. Sevilla, 1993.

CASTAÑo J. y GonzÁlez, J.J.: Constitución y funcionamiento de las cooperativas; J. M. Bosch Editores, Barcelona, 1996.

Del Pozo, F. F.: El fortalecimiento de recursos propios; Marcial Pons, Zaragoza, 1992.

Divar, J.: Lecciones de derecho mercantil. La empresa, el empresario individual, el empresario social, Universidad de Deusto, Bilbao, 1981.

—, La Democracia económica, Universidad de Deusto, Bilbao, 1990.

- La alternativa cooperativa, Barcelona, 1985.

- La metamorfosis del capital. Bases de la empresa futura; Universidad de Deusto, Bilbao, 1983.

FajaRdo García, I.G.: La gestión económica de la cooperativa: responsabilidad de los socios; Tecnos, Madrid, 1997.

FernÁNDEZ GUADAÑo, J.: La nueva estructura financiera de acuerdo con la Ley 27/1999, de cooperativas; REVESCO, REC, Núm. 77, Madrid, 2002.

GarcíA SANz, D.: Concentración de empresas cooperativas: aspectos económico-contables y financieros; CES, Madrid, 2001.

GADEA, E.: Derecho de las cooperativas: análisis de la Ley 4/1993, de 24 de junio, de cooperativas del País Vasco; 2. ${ }^{a}$ ED., Universidad de Deusto, Bilbao, 2001.

-, Evolución de la legislación Cooperativa en España, CSCE, Vitoria, 1999.

García Jiménez, M.: Alcance y límites de la Ley 27/1999 de cooperativas. Los ingresos y las bajas de los socios; AECOOP - EEC, REVESCO, n. ${ }^{\circ} 77, \mathrm{Ma}-$ drid, 2002.

GARCíA SANZ, D.: Concentración de empresas cooperativas - aspectos económico-contables y financieros; CES - Colección Documentación, Madrid, 2001.

Gómez URquijo, L. y De los Ríos AÑón, M.: Respuestas a las dificultades de capital en las cooperativas: el caso de Eroski; Anuario de Estudios Cooperativos, Universidad de Deusto, Bilbao, 1997.

Grávalos Gastaminza, M. ${ }^{a}$ A.: Economía social, Septem Ediciones, Oviedo, 2002.

GutiérRez FérnANDEZ, C.C.: «Economía financiera de las sociedades cooperativas (y de las organizaciones de participación)» in: Sociedades Cooperati- 
vas: Régimen jurídico; Coordinado por José Antonio Prieto Juárez, Ibiden ediciones, Madrid, 1999

Morillas Jarillo, M.J. y Feliú ReY, M.I.: Curso de cooperativas; Tecnos, Madrid, 2002.

PAstor Sempre, C.: «El régimen económico: principales aspectos», in : La sociedad cooperativa en la ley 27/1999, de 16 de julio de Cooperativas; Coordinado por Francisco J. Alonso Espinosa. Comares, Granada, 2001.

Prieto JuÁrez, J. A.: El régimen económico en la vigente legislación cooperativa a la luz de los principios proclamados por la alianza cooperativa internacional en 1995; AECOOP - EEC, REVESCO, n. ${ }^{\circ}$ 77, Madrid, 2002.

RosembuJ, T.: La empresa Cooperativa, CEAC, Barcelona, 1982.

—, Economía Social y Empresa, PPU, Barcelona, 1993.

SANCIS PAlACIO, J. R.: Análisis estratégico de la empresa cooperativa; Tiran Lo Blanc, Valencia, 1995.

SOMMERHOFF, R.W.: Financiamiento cooperativo; Intercoop, Buenos Aires, 1972. URÍA, R.: Derecho Mercantil; Marcial Pons, Ediciones Jurídicas, Madrid, 1994.

VAINSTOK, A.: Estudios de economía cooperativa; Intercoop - CCC, Buenos Aires, 1977.

VICENT Chulí, F.:Introducción al Derecho mercantil; Tirant lo Blanc, Valencia, 1996.

- «El futuro de la legislación cooperativa», in: Cooperativismo y Economía Social. S. P. Universidad de Vigo. N. ${ }^{\circ} 24$ - 2001/2002.

\section{Legislación}

Ley 4/1993, de 24 de junio, de Cooperativas de Euskadi.

Ley 27/1999, de 16 de julio de 1999, General de Cooperativas.

Ley $1 / 2000$, de 29 de junio de 2000, de modificación de la Ley de Cooperativas del País Vasco.

\section{Declaración}

Declaración de la Alianza Cooperativa Internacional sobre la identidad cooperativa. Congreso de Manchester de 23 de septiembre de 1995. 